\title{
Plasma adipokine and inflammatory marker concentrations are altered in obese, as opposed to non-obese, type 2 diabetes patients
}

\author{
Dominique Hansen • Paul Dendale • Milou Beelen • \\ Richard A. M. Jonkers • Annelies Mullens • \\ Luk Corluy $\cdot$ Romain Meeusen $\cdot$ Luc J. C. van Loon
}

Accepted: 12 January 2010 / Published online: 4 February 2010

(C) The Author(s) 2010. This article is published with open access at Springerlink.com

\begin{abstract}
Elevated plasma free fatty acid (FFA), inflammatory marker, and altered adipokine concentrations have been observed in obese type 2 diabetes patients. It remains unclear whether these altered plasma concentrations are related to the diabetic state or presence of obesity. In this cross-sectional observational study, we compare basal plasma FFA, inflammatory marker, and adipokine concentrations between obese and non-obese type 2 diabetes patients and healthy, non-obese controls. A total of 20 healthy, normoglycemic males (BMI $<30 \mathrm{~kg} / \mathrm{m}^{2}$ ), 20 non-
\end{abstract}

Communicated by Jacques Poortmans.

D. Hansen $\cdot$ R. Meeusen

Department of Human Physiology and Sportsmedicine,

Vrije Universiteit Brussel (VUB), Brussels, Belgium

e-mail: Hansen_dominique@yahoo.com

D. Hansen $\cdot$ P. Dendale

Jessa Hospital, Rehabilitation and Health Centre,

Heart Centre Hasselt, Hasselt, Belgium

P. Dendale

Faculty of Medicine, Hasselt University, Hasselt, Belgium

M. Beelen · R. A. M. Jonkers · L. J. C. van Loon ( $\varangle)$

Department of Human Movement Sciences,

Nutrition and Toxicology Research Institute Maastricht

(NUTRIM), Maastricht University Medical Centre+,

6200 MD Maastricht, The Netherlands

e-mail: L.vanLoon@HB.unimaas.nl

\author{
A. Mullens \\ Department of Endocrinology, \\ Jessa Hospital, Hasselt, Belgium \\ L. Corluy \\ Department of Rheumatology, \\ Jessa Hospital, Hasselt, Belgium
}

obese $\left(\right.$ BMI $<30 \mathrm{~kg} / \mathrm{m}^{2}$ ) and 20 obese (BMI $>35 \mathrm{~kg} / \mathrm{m}^{2}$ ) type 2 diabetes patients were selected to participate in this study. Groups were matched for age and habitual physical activity level. Body composition, glycemic control, and exercise performance capacity were assessed. Basal blood samples were collected to determine plasma leptin, adiponectin, resistin, tumor necrosis factor $\alpha(\mathrm{TNF} \alpha)$, interleukin-6 (IL-6), high-sensitivity C-reactive protein (hsCRP) and FFA concentrations. Plasma FFA, inflammatory marker (hsCRP, IL-6, TNF $\alpha$ ), adipokine (adiponectin, resistin, leptin), and triglyceride concentrations did not differ between non-obese diabetes patients and healthy, normoglycemic controls. Plasma FFA, IL-6, hsCRP, leptin, and triglyceride levels were significantly higher in the obese diabetes patients when compared with the healthy normoglycemic controls $(P<0.05)$. Furthermore, plasma hsCRP and leptin levels were significantly higher in the obese versus non-obese diabetes patients $(P<0.05)$. Significant correlations between plasma parameters and glycemic control were observed, but disappeared after adjusting for trunk adipose tissue mass. Elevated plasma leptin, hsCRP, IL-6, and FFA concentrations are associated with obesity and not necessarily with the type 2 diabetic state.

Keywords Obesity · Diabetes · Adipokines · Inflammation $\cdot$ Fat mass

\section{Introduction}

Obesity, and especially visceral adipose tissue accumulation, increases the risk of developing type 2 diabetes (Jensen 2008). The greater risk of type 2 diabetes in the obese can, at least partly, be explained by changes in adipose tissue function (Bastard et al. 2006; Hajer et al. 2008; 
Rasouli and Kern 2008). The classical perception of adipocytes merely as a storage site for excess lipid has changed dramatically over the last decade. This is attributed to the discovery that adipose tissue can function as an active endocrine organ, co-regulating whole-body metabolism. An increase in adipose tissue mass is generally accompanied by an increase in adipocyte size and macrophage infiltration (Otto and Lande 2005). Greater adipose tissue mass, adipocyte hypertrophy, and/or macrophage infiltration strongly modulate adipose tissue lipolysis and the secretion of numerous cytokines and adipokines (Hajer et al. 2008; Wellen and Hotamisligil 2003). In accordance, elevated plasma free fatty acid (FFA), leptin, resistin, tumor necrosis factor $\alpha(\mathrm{TNF} \alpha)$ and interleukin-6 (IL-6) concentrations have been reported in the obese (Bastard et al. 2006; Hajer et al. 2008; Rasouli and Kern 2008). In contrast, circulating plasma adiponectin concentrations have been reported to be reduced in the obese state. Furthermore, an increase in circulating IL-6 concentration stimulates C-reactive protein (CRP) synthesis in the liver (Bastard et al. 2006). Eventually, altered plasma adipokine, inflammatory factor, and/or FFA levels can contribute to the development and/or progression of liver and skeletal muscle insulin resistance, and induce pancreatic $\beta$-cell apoptosis (Hajer et al. 2008).

The proposed impact of altered endocrine function of adipose tissue on the development and/or progression of type 2 diabetes has generally been studied in vivo in human cross-sectional studies. In these studies, the above-mentioned plasma parameters have been assessed and compared between type 2 diabetes patients and normoglycemic controls (Al-Daghri et al. 2003; Al-Harithy and Al-Ghamdi 2005; Bastard et al. 2002; Bullo et al. 2002; Carey et al. 2004; Haffner et al. 1996; Heilbronn et al. 2004; Kim et al. 2006; Liu et al. 1999; Miyazaki et al. 2003; Putz et al. 2004; Rieusset et al. 2004; Sivitz et al. 2003; Tatti et al. 2001; Merwe van der et al. 2001; Yu et al. 2002). In general, most of the type 2 diabetes patients included in these studies were obese. Therefore, it remains unclear whether the observed alterations in plasma FFA's, adipokines, and/or inflammatory parameters in type 2 diabetes patients are due to excess adipose tissue mass and/or directly associated with the type 2 diabetic state. To differentiate between the impact of obesity and type 2 diabetes on the altered plasma FFA, adipokine, and/or inflammatory profiles several groups have compared plasma profiles between lean and obese type 2 diabetes patients (Abdelgadir et al. 2005; Bahceci et al. 2007; Chanchay et al. 2006; Hasegawa et al. 2005; Hotta et al. 2000; Marita et al. 2005; Sayeed et al. 2003; Yang et al. 2006). Elevated plasma FFA and IL-6, but unaltered TNF $\alpha$, levels have been reported in non-obese T2DM patients, when compared with body mass index matched normoglycemic controls (Bahceci et al. 2007; Yang et al. 2006). Whether plasma C-reactive protein, adiponectin, leptin, and/or resistin concentrations are altered in non-obese type 2 diabetes patients when compared with healthy controls, remains unclear (Abdelgadir et al. 2005; Bahceci et al. 2007; Chanchay et al. 2006; Hasegawa et al. 2005; Hotta et al. 2000; Marita et al. 2005; Sayeed et al. 2003; Yang et al. 2006). So far, these data have only been obtained in Asian and Mid-Eastern populations. Due to apparent differences in adipose tissue distribution (Banerji et al. 1999) and the level of insulin resistance (Chandalia et al. 1999) between ethnic groups, these findings do not necessarily apply to a Caucasian population. Moreover, in none of these studies habitual physical activity was controlled between groups. Different levels of habitual physical activity might affect plasma adipokine and inflammatory marker levels (You and Nicklas 2008). Clearly, proper control of habitual activity is warranted when comparing such plasma parameters between groups.

We hypothesize that altered plasma adipokine, inflammatory factor, and/or FFA levels are related to the obese state only and are not prevalent in non-obese type 2 diabetes patients. The present study compares basal plasma FFA's, adipokines, and inflammatory markers between obese and non-obese type 2 diabetes patients versus nonobese, normoglycemic controls. This comparison increases our insight in the proposed impact of obesity in the development and/or progression of type 2 diabetes.

\section{Methods}

\section{Subjects}

A total of 60 Caucasian males were selected to participate in this study: 20 non-obese (BMI $<30 \mathrm{~kg} / \mathrm{m}^{2}$ ) and 20 obese (BMI $>35 \mathrm{~kg} / \mathrm{m}^{2}$ ) type 2 diabetes patients, and 20 healthy, non-obese subjects (BMI $<30 \mathrm{~kg} / \mathrm{m}^{2}$; see Table 1). Type 2 diabetes patients had been diagnosed for at least 12 months prior to investigation and were all treated with oral blood glucose lowering medication. All subjects were sedentary and had not participated in any regular exercise and/or caloric intake restriction program for at least 5 years. Subjects were informed about the nature and risks of the experimental procedures before their written informed consent was obtained. This study was approved by the local medical ethical committee of the Jessa Hospital.

\section{Study design}

Overall, groups were matched for age and habitual physical activity. The latter was estimated by the use of the IPAQ questionnaire. Additionally, non-obese type 2 diabetes patients and normoglycemic controls were matched for body mass index. Non-obese and obese type 2 diabetes 
Table 1 Subjects' characteristics
Data represent means \pm SEM

Fasting glucose, insulin, HOMA index, and AUC OGTT were all determined from an OGTT performed after 3 days of discontinuation of habitual use of oral blood glucose and lipid lowering medication

HOMA homeostasis model assessment, $H b A_{1 \mathrm{c}}$ glycosylated hemoglobin, $A U C$ area under the curve, $O G T T$ oral glucose tolerance test, $H D L$ high-density lipoprotein, $L D L$ low-density lipoprotein, $V O_{2 \text { peak }}$ peak wholebody oxygen uptake capacity, $W_{\max }$ maximal workload capacity

Leg fat free and adipose tissue mass are expressed as average of the two legs

* Significantly different between non-obese and obese T2DM patients $(P<0.05)$

¥ Significantly different compared with healthy controls $(P<0.05)$

\begin{tabular}{|c|c|c|c|}
\hline & $\begin{array}{l}\text { Healthy } \\
\text { controls }\end{array}$ & $\begin{array}{l}\text { Non-obese } \\
\text { diabetes }\end{array}$ & $\begin{array}{l}\text { Obese } \\
\text { diabetes }\end{array}$ \\
\hline Number & 20 & 20 & 20 \\
\hline Age (years) & $55 \pm 1$ & $58 \pm 1$ & $56 \pm 1$ \\
\hline Body mass index $\left(\mathrm{kg} / \mathrm{m}^{2}\right)$ & $26.1 \pm 0.4$ & $26.6 \pm 0.4$ & $35.6 \pm 0.6^{* *}$ \\
\hline Body weight $(\mathrm{kg})$ & $79.9 \pm 1.7$ & $81.2 \pm 1.5$ & $108.4 \pm 2.8^{*}$ \\
\hline \multicolumn{4}{|l|}{ Glycemic control } \\
\hline Fasting glucose $(\mathrm{mmol} / \mathrm{L})$ & $5.8 \pm 0.2$ & $9.7 \pm 0.6^{\ddagger}$ & $10.9 \pm 0.8^{\ddagger}$ \\
\hline AUC OGTT (mol min/L) & $0.92 \pm 0.04$ & $1.76 \pm 0.09^{\ddagger}$ & $1.86 \pm 0.09^{\ddagger}$ \\
\hline Disease duration (years) & $0 \pm 0$ & $6.2 \pm 1.2^{\ddagger}$ & $4.5 \pm 0.9^{\ddagger}$ \\
\hline Insulin $(\mathrm{mU} / \mathrm{L})$ & $10.3 \pm 0.9$ & $12.1 \pm 1.2$ & $21.6 \pm 2.6^{* \#}$ \\
\hline HOMA index & $2.6 \pm 0.2$ & $5.2 \pm 0.7^{\ddagger}$ & $9.6 \pm 0.9^{* \ddagger}$ \\
\hline $\mathrm{HbA}_{1 \mathrm{c}}(\%)$ & $5.4 \pm 0.1$ & $7.0 \pm 0.2^{\ddagger}$ & $8.0 \pm 0.4^{* \ddagger}$ \\
\hline \multicolumn{4}{|l|}{ Blood lipid profile } \\
\hline Total cholesterol (mmol/L) & $5.6 \pm 0.2$ & $5.0 \pm 0.2$ & $5.3 \pm 0.2$ \\
\hline HDL cholesterol $(\mathrm{mmol} / \mathrm{L})$ & $1.4 \pm 0.1$ & $1.2 \pm 0.1$ & $1.1 \pm 0.1^{\ddagger}$ \\
\hline LDL cholesterol $(\mathrm{mmol} / \mathrm{L})$ & $3.7 \pm 0.2$ & $3.3 \pm 0.2$ & $3.6 \pm 0.1$ \\
\hline Triglycerides $(\mathrm{mmol} / \mathrm{L})$ & $1.4 \pm 0.1$ & $1.2 \pm 0.2$ & $2.2 \pm 0.2^{* \sharp}$ \\
\hline \multicolumn{4}{|l|}{ Body composition } \\
\hline Adipose tissue mass legs ( $\mathrm{kg}$ ) & $5.2 \pm 0.4$ & $4.6 \pm 0.3$ & $9.2 \pm 0.6^{* \ddagger}$ \\
\hline Adipose tissue mass trunk $(\mathrm{kg})$ & $13.2 \pm 0.7$ & $14.4 \pm 0.6$ & $26.2 \pm 1.2^{* \ddagger}$ \\
\hline Adipose tissue mass total body $(\mathrm{kg})$ & $20.9 \pm 1.1$ & $21.8 \pm 0.9$ & - \\
\hline Fat free mass legs (kg) & $18.3 \pm 0.4$ & $17.3 \pm 0.4$ & $19.4 \pm 0.5$ \\
\hline Fat free mass trunk $(\mathrm{kg})$ & $27.7 \pm 0.6$ & $29.0 \pm 0.5$ & $32.8 \pm 0.8^{* *}$ \\
\hline \multicolumn{4}{|l|}{ Exercise performance capacity } \\
\hline $\mathrm{VO}_{2 \text { peak }}(\mathrm{L} / \mathrm{min})$ & $2.5 \pm 0.1$ & $2.3 \pm 0.1$ & $2.1 \pm 0.1$ \\
\hline $\mathrm{VO}_{2 \text { peak }}(\mathrm{mL} / \mathrm{kg}$ leg fat free mass $/ \mathrm{min})$ & $135 \pm 6$ & $131 \pm 7$ & $107 \pm 5^{* \ddagger}$ \\
\hline$W_{\max }$ & $221 \pm 10$ & $174 \pm 30^{\ddagger}$ & $155 \pm 37^{\ddagger}$ \\
\hline Habitual physical activity (min/week) & $118 \pm 33$ & $72 \pm 24$ & $80 \pm 33$ \\
\hline Smokers (n) & 2 & 2 & 3 \\
\hline
\end{tabular}

patients were matched for basal fasting glucose concentrations. Fasting blood samples were collected to compare glycosylated hemoglobin $\left(\mathrm{HbA}_{1 \mathrm{c}}\right)$ content, blood lipid profile, insulin, adiponectin, resistin, leptin, interleukin-6, high-sensitivity C-reactive protein, TNF $\alpha$, and FFA concentrations between groups. Moreover, HOMA index, fat free mass and whole-body oxygen uptake and workload capacity were compared between groups. All measurements were performed at the same time during the day (between 8.00 and $12.00 \mathrm{AM}$ ).

Medication, diet and physical activity prior to testing

Three days prior to testing subjects abstained from taking oral blood glucose and/or lipid lowering medication. All subjects maintained normal physical activity and dietary patterns, and refrained from any sort of heavy physical exercise/labor for at least 3 days prior to testing. The evening prior to the test day, all subjects received the same standardized meal $\left(45 \pm 1 \mathrm{~kJ} \mathrm{~kg}^{-1}\right.$, consisting of 33 energy\% (En\%) carbohydrate, 47 En\% fat, and 20 En\% protein). Daily habitual physical activity over the last 2 weeks was estimated by the International Physical Activity Questionnaire (IPAQ) (Craig et al. 2003).

Blood analysis

Subjects arrived at the hospital by car or public transportation and reported at the laboratory at 08.00 AM after an overnight fast. After $20 \mathrm{~min}$ of rest a venous blood sample was collected. Thereafter, a $2 \mathrm{~h}$ oral glucose tolerance test (OGTT) was performed. Plasma samples were immediately centrifuged at $1,000 \mathrm{~g}$ and $4^{\circ} \mathrm{C}$ for $5 \mathrm{~min}$, after which aliquots of plasma were frozen in liquid nitrogen and stored at $-80^{\circ} \mathrm{C}$ until analysis. Blood samples were analyzed for glucose (Beckman Synchron LX 20 Analyser, Beckman Coulter Inc., USA), insulin (Advia Centaur Immunoassay System, Bayer Diagnostics Inc., USA), total cholesterol, 
high-density lipoprotein (HDL) cholesterol, low-density lipoprotein (LDL) cholesterol, and total plasma triglycerides (Beckman Synchron LX 20 Analyser, Beckman Coulter Inc., USA). HOMA index was calculated to estimate wholebody insulin sensitivity: [(insulin ${ }_{(\mathrm{mU} / \mathrm{L})} \times$ glucose $\left._{(\mathrm{mmol} / \mathrm{L})}\right] /$ 22.5. Plasma adiponectin concentrations were assessed using a commercially available Human Adiponectin ELISA assay kit (HADP-61K, Linco Research Inc., St. Charles, MO, USA). TNF $\alpha$ concentrations were determined using a solid-phase, chemiluminescent immunometric assay (IMMULITE TNF- $\alpha$, DPC Biermann GmbH, Bad Nauheim, Germany). Plasma high-sensitivity $\mathrm{C}$-reactive protein (hsCRP) concentrations were measured by means of immunoephelometry (Cardiophase, Dade Behring GmbH, Marburg, Germany). Resistin concentrations were assessed by enzyme-substrate reaction with a commercially available assay kit (ELISA, Phoenix Pharmaceuticals, USA). Plasma free fatty acid (FFA) levels were quantified by enzymatic method using a commercially available assay kit from Wako Chemicals GmbH, Germany. Plasma interleukin-6 (IL-6) levels were assessed by a solid-phase, enzym-labeled, chemiluminiscent sequential immunometric assay (IMMULITE 1000 analyzer, EURO/DPC Ltd, UK). In addition, a small blood sample was used to determine blood $\mathrm{HbA}_{1 \mathrm{c}}$ content (Hi-Auto A1c Analyser, Menarini Diagnostics Inc., Italy).

Whole-body oxygen uptake capacity

Peak whole-body oxygen uptake capacity $\left(\mathrm{VO}_{2 \text { peak }}\right)$ and workload capacity $\left(W_{\max }\right)$ was assessed during an exhaustive incremental exercise test on a calibrated cycle ergometer (Ergo 1500 cycle, Ergofit GmbH, Pirmasens, Germany) using a 3-min work stage protocol (Fletcher et al. 2001). Oxygen uptake $\left(\mathrm{VO}_{2}\right)$ measurements were performed continuously (CS 200, Schiller AG, Switzerland). The heart was monitored using a 12-lead electrocardiogram with heart rate being recorded continuously.

Body composition

Body mass was measured using a calibrated analogue weight scale (Tanita model TBF-300, Tanita Corp., Tokyo, Japan). Segmental and whole-body adipose tissue mass and fat free mass were determined using whole-body dual X-ray absorptiometry (Lunar DPXL, Wisconsin, USA) (Glickman et al. 2004). In healthy subjects and nonobese type 2 diabetes patients, whole-body as well as segmental (legs and trunk) adipose tissue and fat free mass were assessed. However, in the obese diabetes patients, only segmental (legs and trunk) adipose tissue and fat free mass were assessed, as the arms did not fit properly under the scanner.
Statistical analysis

Data are expressed as means \pm SEM. To compare three groups simultaneously, multiple one-way analysis of variance (MANOVA), with Tukey's post hoc test, were applied. In addition, relations between parameters were analyzed by Pearson correlation coefficients or by multiple regression analysis. Statistical significance was set at $P<0.05$. All calculations were performed using the Statistical Package for the Social Sciences v. 15.0 (SPSS).

\section{Results}

Subjects

A total of 20 Caucasian, non-obese and obese type 2 diabetes patients, and 20 non-obese normoglycemic controls were included in this study (Table 1). The diabetes patients were all using oral blood glucose lowering medication (sulfamides $25 \%$, biguanides $70 \%, \alpha$-glucosidase inhibitors $2 \%$, thiazolidinediones $7 \%$, and glinides $10 \%$ ) and had been diagnosed with type 2 diabetes for $5.4 \pm 0.7$ years. Non-obese type 2 diabetes patients and normoglycemic controls were matched for body mass index. Trunk and whole-body adipose tissue mass were similar between groups $(P>0.05)$. In addition, non-obese and obese type 2 diabetes patients were matched for fasting blood glucose. In accordance, oral glucose tolerance and time since diagnosis did not differ between groups $(P>0.05)$. Habitual physical activity patterns did not differ between normoglycemic controls, non-obese and obese type 2 diabetes patients $(P>0.05)$.

Glycemic control

Glycemic control was significantly impaired in non-obese and obese diabetes patients when compared with healthy, normoglycemic controls (as indicated by AUC during OGTT; $P<0.05)$. In addition, blood $\mathrm{HbA}_{1 \mathrm{c}}$ content, fasting insulin, and HOMA index were significantly elevated in the obese compared with non-obese type 2 diabetes patients (Table $1 ; P<0.05$ ).

Blood lipid profile

Plasma HDL cholesterol levels were significantly lower in obese diabetes patients when compared with normoglycemic controls $(P<0.05)$. Plasma triglyceride levels were significantly higher in the obese when compared with non-obese patients and normoglycemic controls $(P<0.05)$. 
Fig. 1 Plasma FFA, inflammatory marker and adipokine concentrations. Data are expressed as means \pm SEM. *Significantly different between obese T2DM patients and other subgroups $(P<0.05)$. No significant differences were found between healthy subjects and non-obese T2DM patients $(P>0.05)$. Plasma leptin (a), adiponectin (b), resistin (c), free fatty acid (d), interleukin-6 (e), high-sensitivity $\mathrm{C}$-reactive protein $(\mathbf{f})$, and tumor necrosis factor $\alpha(\mathbf{g})$ concentrations
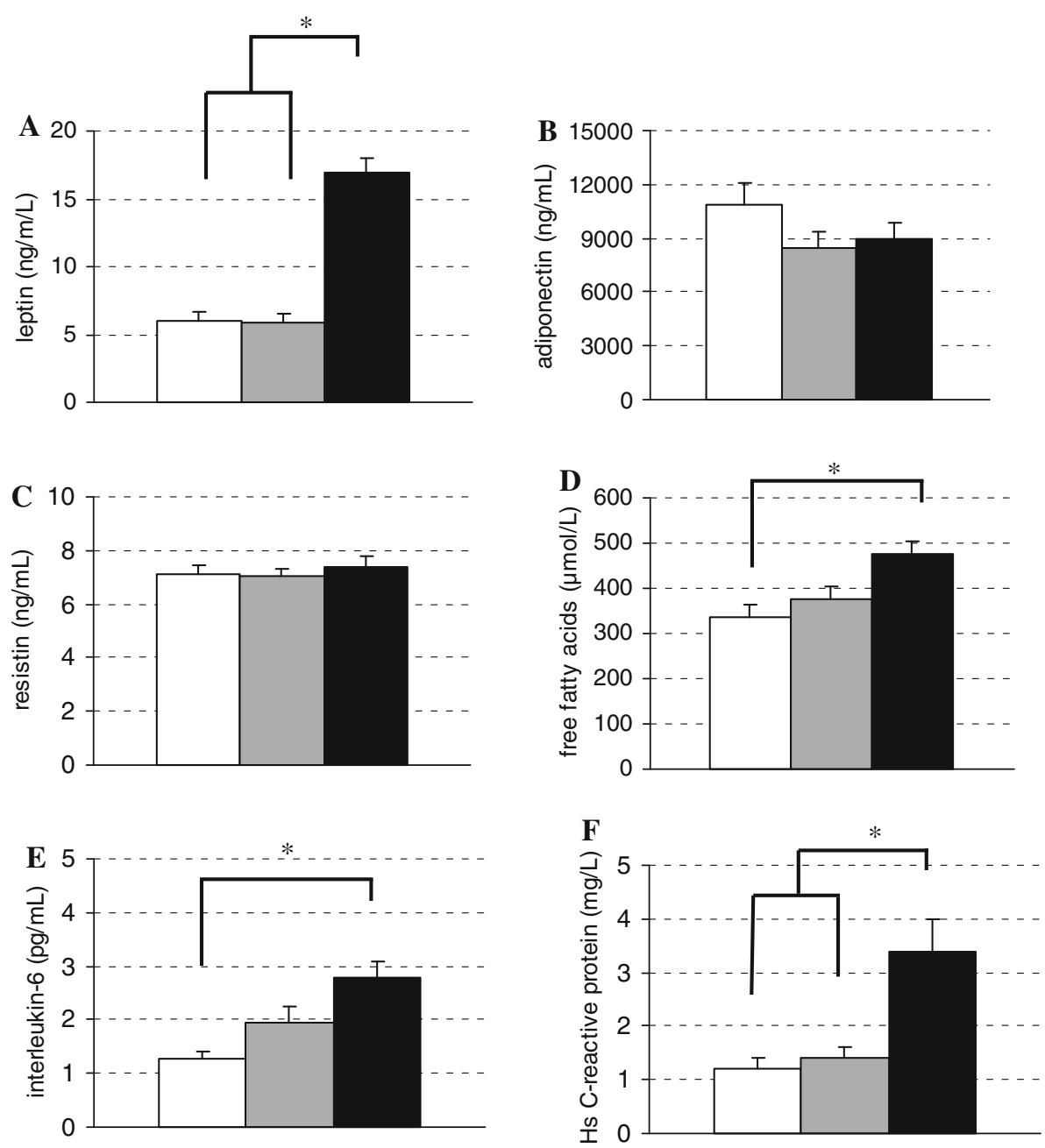

Healthy subjects

Non-obese T2DM patients

Obese T2DM patients



Exercise performance capacity

Whole-body oxygen uptake capacity $\left(\mathrm{VO}_{2 \text { peak }}\right)$ did not differ significantly between groups (Table 1). When expressed per $\mathrm{kg}$ leg fat free mass, $\mathrm{VO}_{2 \text { peak }}$ was significantly lower in the obese when compared with non-obese type 2 diabetes patients and normoglycemic controls $(P<0.05)$. Maximal workload capacity $\left(W_{\max }\right)$ was significantly greater in normoglycemic controls when compared with obese and non-obese diabetes patients $(P<0.05)$.
Plasma adipokines and free fatty acids

Basal plasma adipokine (adiponectin, leptin, resistin), FFA, and inflammatory marker (hsCRP, IL-6) concentrations are presented in Fig. 1. No significant differences were observed between non-obese diabetes patients and normoglycemic controls $(P>0.05)$. Plasma FFA, IL-6, hsCRP, and leptin levels were significantly higher in obese diabetes patients when compared with normoglycemic controls $(P<0.05)$. Furthermore, plasma hsCRP and leptin levels 
Table 2 Univariate correlations of blood parameters, adipose tissue mass, and $\mathrm{VO}_{2 \text { peak }}$ with glycemic control
Values provided in this table represent $R$ values; only significant correlations are mentioned in this table $(P<0.05)$

$A U C$ area under the curve, OGTT oral glucose tolerance test, HOMA homeostasis model assessment, $V O_{2 \text { peak }}$ peak wholebody oxygen uptake capacity, $H b A_{1 \mathrm{c}}$ glycosylated hemoglobin

\begin{tabular}{|c|c|c|c|c|}
\hline & \multicolumn{4}{|c|}{ Glycemic control } \\
\hline & $\begin{array}{l}\text { AUC } \\
\text { OGTT }\end{array}$ & $\begin{array}{l}\text { Fasting glucose } \\
(\mathrm{mmol} / \mathrm{L})\end{array}$ & $\begin{array}{l}\mathrm{HbA}_{1 \mathrm{c}} \\
(\%)\end{array}$ & $\begin{array}{l}\text { HOMA } \\
\text { index }\end{array}$ \\
\hline \multicolumn{5}{|l|}{ Blood parameters } \\
\hline Free fatty acids $(\mu \mathrm{mol} / \mathrm{L})$ & 0.50 & 0.48 & 0.53 & 0.46 \\
\hline \multicolumn{5}{|l|}{ Adiponectin (ng/mL) } \\
\hline Leptin $(\mathrm{ng} / \mathrm{mL})$ & 0.46 & 0.51 & 0.62 & 0.72 \\
\hline \multicolumn{5}{|l|}{ Resistin (ng/mL) } \\
\hline High-sensitivity C-reactive protein $(\mathrm{mg} / \mathrm{L})$ & 0.45 & 0.44 & 0.39 & 0.56 \\
\hline Interleukin-6 (pg/mL) & 0.50 & 0.47 & 0.44 & 0.37 \\
\hline \multicolumn{5}{|l|}{ Tumor necrosis factor $\alpha(\mathrm{pg} / \mathrm{mL})$} \\
\hline \multicolumn{5}{|l|}{ Body composition } \\
\hline Trunk adipose tissue mass $(\mathrm{kg})$ & 0.51 & 0.54 & 0.63 & 0.69 \\
\hline Leg adipose tissue mass $(\mathrm{kg})$ & 0.38 & 0.44 & 0.50 & 0.56 \\
\hline \multicolumn{5}{|l|}{ Exercise performance capacity } \\
\hline $\mathrm{VO}_{2 \text { peak }}(\mathrm{L} / \mathrm{min})$ & -0.29 & -0.33 & -0.26 & -0.31 \\
\hline $\mathrm{VO}_{2 \text { peak }}(\mathrm{mL} / \mathrm{min} / \mathrm{kg}$ leg fat free mass $)$ & -0.29 & -0.36 & -0.31 & -0.48 \\
\hline
\end{tabular}

were significantly elevated in obese versus non-obese diabetes patients $(P<0.05)$.

Correlations and multivariate regression analysis

Univariate correlations between plasma factors, adipose tissue mass, $\mathrm{VO}_{2 \text { peak }}$, and glycemic control are displayed in Table 2. In total subject population, plasma FFA, leptin, hsCRP, and IL-6 concentrations correlated significantly with measures of glycemic control $(P<0.05)$. These correlations were no longer evident when plasma concentrations were adjusted for trunk adipose tissue mass in multivariate regression analysis $(P>0.05)$.

\section{Discussion}

The present study compares basal plasma adipokine, inflammatory marker, and FFA concentrations between non-obese and obese type 2 diabetes patients versus nonobese normoglycemic controls. We show that basal plasma FFA, high-sensitivity C-reactive protein (hsCRP), interleukin-6 (IL-6), leptin, and triglyceride levels are elevated in obese type 2 diabetes patients, as opposed to healthy, normoglycemic controls (Fig. 1; Table 1). On the other hand, no such differences were found between non-obese type 2 diabetes patients and healthy normoglycemic controls. Consequently, altered plasma FFA, IL-6, hsCRP, and leptin levels seem to be more related to adipose tissue mass than to the presence or absence of the type 2 diabetic state and/or the level of glycemic control. This is further supported by the observation that parameters that assess glycemic control were no longer correlated with plasma FFA, IL-6, hsCRP and leptin levels when data were adjusted for trunk adipose tissue mass (Table 2). Therefore, our findings suggest that elevated basal plasma FFA, IL-6, hsCRP, and leptin concentrations are not necessarily related to the type 2 diabetic state.

Our findings seem to be in contrast with findings from some, but not all, studies which show that in non-obese type 2 diabetes patients, plasma FFA, IL-6, and CRP concentrations are higher, and adiponectin and leptin levels are lower, when compared with matched normoglycemic controls (Abdelgadir et al. 2005; Bahceci et al. 2007; Chanchay et al. 2006; Hasegawa et al. 2005; Hotta et al. 2000; Marita et al. 2005; Sayeed et al. 2003; Yang et al. 2006). This might be attributed to differences in the ethnic background of the volunteers in the different studies (Carroll et al. 2009; Lee and Jensen 2009; Reimann et al. 2007), which show large differences in adipose tissue mass distribution and/or the level of insulin resistance (Banerji et al. 1999; Chandalia et al. 1999). For example, Asian and Mid-Eastern populations show a relatively greater truncal adipose tissue mass when compared with BMI-matched Caucasians (Banerji et al. 1999; Chandalia et al. 1999). This might be accompanied by differences in adipokine and inflammatory marker secretion between populations of various ethnic backgrounds. Additionally, in none of these studies habitual physical activity was controlled for between groups. Different levels of habitual activity are likely to affect plasma adipokine and inflammatory marker levels, complicating the interpretation of such findings (You and Nicklas 2008).

Recent in vitro studies examined the relation between adipocyte size and adipokine/inflammatory factor release/ 
expression derived from Caucasian human subcutaneous adipose tissue biopsies (Jernas et al. 2006; Skurk et al. 2007). These studies indicate that leptin and IL-6 secretion were significantly greater in enlarged adipocytes. No such relation was observed for adipocyte size and $\mathrm{TNF} \alpha$ and/or adiponectin release. Moreover, a correlation between serum amyloid A (SAA) gene expression in human adipocytes and adipocyte size has previously been reported (Jernas et al. 2006). SAA is an acute-phase protein involved in inflammation, and contributes to adipocyte-derived CRP and IL- 6 release. A correlation between adipocyte-derived FFA release and adipocyte size has been well-established. These findings seem to agree with our observation that plasma hsCRP, FFA, leptin and IL-6 are no longer significantly correlated with the level of glycemic control when adjusted for trunk adipose tissue mass. Consequently, we conclude that alterations in plasma FFA, IL-6, hsCRP, and leptin levels in obese type 2 diabetes patients are attributed to the greater adipose tissue mass, and not necessarily to the presence of the type 2 diabetic state.

Data from the present study imply that systemic lowgrade inflammation, a disturbed blood lipid profile, and lowered oxygen uptake capacity are more prevalent in obese, as opposed to non-obese, type 2 diabetes patients. The development of type 2 diabetes in subjects with excess adipose tissue mass is currently believed to be related to many factors. Besides genetic predisposition and ethnicity, a low skeletal muscle oxidative capacity and/or altered protein/cytokine secretion from adipocytes is linked to impairments in whole-body carbohydrate metabolism. However, we failed to observe any significant differences in wholebody oxygen uptake capacity and/or blood plasma adipokine and inflammatory markers levels in the non-obese type 2 diabetes patients when compared to the matched normoglycemic controls. Therefore, other factors are likely to play a more prominent role in the etiology of insulin resistance and type 2 diabetes in the non-obese population.

One of the more challenging features of this work was the inclusion of non-obese type 2 diabetes patients. Recent studies report that only $\sim 10 \%$ of all Caucasian type 2 diabetes patients have a normal lean phenotype, whereas more than $60 \%$ is obese (Kramer et al. 2009). Nonetheless, the comparison of plasma adipokine and inflammatory marker concentrations in non-obese and obese type 2 diabetes patients generates the possibility to differentiate between the impact of type 2 diabetes and obesity.

This study has some important clinical implications. The presented data confirm that obese type 2 diabetes patients are clearly at a high risk of developing cardiovascular disease (based on body composition, blood lipid profile and inflammation parameters, oxygen uptake capacity). Based on these parameters, the non-obese type 2 diabetes patients seem to be at a lower risk of developing cardiovascular complications. Since strong correlations have been reported between low-grade inflammation, disturbed blood lipid profile, reduced whole-body oxidative capacity, and the risk of developing cardiovascular complications, obese type 2 diabetes patients should be stimulated to adhere to effective exercise, nutritional, and pharmaceutical intervention to reduce excess adipose tissue mass and improve glycemic control. Interestingly, our data show that the proposed link between plasma adipokines, inflammation parameters, FFA and type 2 diabetes are more related to the level of adiposity, as opposed to insulin sensitivity and/or glycemic control. Further study remains warranted to elucidate the proposed role of these plasma parameters in the etiology of obesity and/or type 2 diabetes.

In conclusion, elevated plasma FFA, IL-6, hsCRP, leptin, and triglyceride concentrations are observed in obese, as opposed to non-obese, type 2 diabetes patients. Elevated plasma leptin, hsCRP, IL-6, and FFA concentrations are attributed to the prevalence of obesity and not necessarily associated with the type 2 diabetic state.

Acknowledgments This work was supported by an unrestricted grant from the clinical research foundation Hartcentrum Hasselt.

Conflict of interest statement None.

Open Access This article is distributed under the terms of the Creative Commons Attribution Noncommercial License which permits any noncommercial use, distribution, and reproduction in any medium, provided the original author(s) and source are credited.

\section{References}

Abdelgadir M, Elbagir M, Eltom M, Berne C, Ahrén B (2005) Reduced leptin concentrations in subjects with type 2 diabetes mellitus in Sudan. Metabolism 51:304-306

Al-Daghri N, Al-Rubean K, Bartlett WA, Al-Attas O, Jones AF, Kumar S (2003) Serum leptin is elevated in Saudi Arabian patients with metabolic syndrome and coronary artery disease. Diabet Med 20:832-837

Al-Harithy RN, Al-Ghamdi S (2005) Serum resistin, adiposity and insulin resistance in Saudi women with type 2 diabetes mellitus. Ann Saudi Med 25:283-287

Bahceci M, Gokalp D, Bahceci S, Tuzcu A, Atmaca S, Arikan S (2007) The correlation between adiposity and adiponectin, tumor necrosis factor alpha, interleukin-6 and high-sensitivity c-reactive protein levels. Is adipocyte size associated with inflammation in adults? J Endocrinol Invest 30:210-214

Banerji MA, Faridi N, Atluri R, Chaiken RL, Lebovitz HE (1999) Body composition, visceral fat, leptin, and insulin resistance in Asian Indian men. J Clin Endocrinol Metab 84:137-144

Bastard JP, Maachi M, Tran Van Nhieu J, Jardel C, Bruckert E, Grimaldi A, Robert JJ, Capeau J, Hainque B (2002) Adipose tissue IL-6 content correlates with resistance to insulin activation of glucose uptake both in vivo and in vitro. J Clin Endocrinol Metab 87:2084-2089

Bastard JP, Maachi M, Lagathu C, Kim MJ, Caron M, Vidal H, Capeau J, Feve B (2006) Recent advances in the relationship between obesity, inflammation, and insulin resistance. Eur Cytokine Netw 17:4-12 
Bullo M, Garcia-Lorda P, Salas-Salvado J (2002) Plasma soluble tumor necrosis factor alpha receptors and leptin levels in normalweight and obese women: effect of adiposity and diabetes. Eur J Endocrinol 146:325-331

Carey AL, Bruce CR, Sacchetti M, Anderson MJ, Olsen DB, Saltin B, Hawley JA, Febbraio MA (2004) Interleukin-6 and tumor necrosis factor- $\alpha$ are not increased in patients with type 2 diabetes: evidence that plasma interleukin-6 is related to fat mass and not insulin responsiveness. Diabetologia 47:1029-1037

Carroll JF, Fulda KG, Chiapa AL, Rodriquez M, Phelps DR, Cardarelli KM, Vishwanatha JK, Cardarelli R (2009) Impact or race/ethnicity on the relationship between visceral fat and inflammatory biomarkers. Obesity 17:1420-1427

Chanchay S, Tungtrongchitr R, Harnroongroj T, Phonrat B, Rungseesakorn O, Paksanont S, Pooudong S, Saowakontha S, Varongchayakul C (2006) Plasma resistin, insulin concentration in non-diabetic and diabetic, overweight/obese Thai. Int J Vitam Nutr Res 76:125-131

Chandalia M, Abate N, Garg A, Strey-Dandersen J, Grundy SM (1999) Relationships between generalized and upper body obesity to insulin resistance in Asian Indian men. J Clin Endocrinol Metab 84:2329-2335

Craig CL, Marshall AL, Sjöström M, Bauman AE, Booth ML, Ainsworth BE, Pratt M, Ekelund U, Yngve A, Sallis JF, Oja P (2003) International physical activity questionnaire: 12-country reliability and validity. Med Sci Sports Exerc 35:1381-1395

Fletcher GF, Balady GJ, Amsterdam EA, Chaitman B, Eckel R, Fleg J, Froelicher VF, Leon AS, Piña IL, Rodney R, Simons-Morton DA, Williams MA, Bazzarre T (2001) Exercise standards for testing and training: a statement for healthcare professionals from the American Heart Association. Circulation 104:1694-1740

Glickman SG, Marn CS, Supiano MA, Dengel DR (2004) Validity and reliability of dual-energy X-ray absorptiometry for the assessment of abdominal adiposity. J Appl Physiol 97:509-514

Haffner SM, Stern MP, Miettinen H, Wei M, Gingerich RL (1996) Leptin concentrations in diabetic and nondiabetic MexicanAmericans. Diabetes 45:822-824

Hajer GR, van Haeften TW, Visseren FLJ (2008) Adipose tissue dysfunction in obesity, diabetes, and vascular diseases. Eur Heart J 29:2959-2971

Hasegawa G, Ohta M, Ichida Y, Obayashi H, Shigeta M, Yamasaki M, Fukui M, Yoshikawa T, Nakamura N (2005) Increased serum resistin levels in patients with type 2 diabetes are not linked with markers of insulin resistance and adiposity. Acta Diabetol 42:104-109

Heilbronn LK, Rood J, Janderova L, Albu JB, Kelley DE, Ravussin E, Smith SR (2004) Relationship between serum resistin concentrations and insulin resistance in nonobese, obese, and obese diabetic subjects. J Clin Endocrinol Metab 89:1844-1848

Hotta K, Funahashi T, Arita Y, Takahashi M, Matsuda M, Okamoto Y, Iwahashi H, Kuriyama H, Ouchi N, Maeda K, Nishida M, Kihara S, Sakai N, Nakajima T, Hasegawa K, Muraguchi M, Ohmoto Y, Nakamura T, Yamashita S, Hanafusa T, Matsuzawa Y (2000) Plasma concentrations of a novel, adipose-specific protein, adiponectin, in type 2 diabetes patients. Arterioscler Thromb Vasc Biol 20:1595-1599

Jensen MD (2008) Role of body fat distribution and the metabolic complications of obesity. J Clin Endocrinol Metab 93:S57-S63

Jernas M, Palming J, Sjöholm K, Jennische E, Svensson PA, Gabrielsson BG, Levin M, Sjögren A, Rudemo M, Lystig TC, Carlsson B, Carlsson LM, Lönn M (2006) Seperation of human adipocytes by size: hypertrophic fat cells display distinct gene expression. FASEB J 20:E832-E839
Kim C, Park J, Park J, Kang E, Ahn C, Cha B, Lim S, Kim K, Lee H (2006) Comparison of body fat composition and serum adiponectin levels in diabetic obesity and non-diabetic obesity. Obesity 14:1164-1171

Kramer H, Cao G, Dugas L, Luke A, Cooper R, Durazo-Arvizu R (2009) Increasing BMI and waist circumference and prevalence of obesity among adults with type 2 diabetes: the National Health and Nutrition Examination Surveys. J Diabetes Complicat [e-pub ahead of print]

Lee S, Jensen MD (2009) Adipogenic risk factor differences between Korean and white adults - potential role of plasma free fatty acid and adiponectin. Metabolism 58:270-274

Liu J, Askari H, Dagogo-Jack S (1999) Basal and stimulated plasma leptin in diabetic subjects. Obes Res 7:537-544

Marita AR, Sarkar JA, Rane S (2005) Type 2 diabetes in non-obese Indian subjects is associated with reduced leptin levels: study from Mumbai, Western India. Mol Cell Biochem 275:143-151

Merwe van der MT, Schlaphoff GP, Crowther NJ, Boyd IH, Gray IP, Joffe BI, Lönnroth PN (2001) Lactate and glycerol release from adipose tissue in lean, obese, and diabetic women from South Africa. J Clin Endocrinol Metabol 86:3296-3303

Miyazaki Y, Pipek R, Mandarino LJ, DeFronzo RA (2003) Tumor necrosis factor alpha and insulin resistance in obese type 2 diabetic patients. Int J Obes 27:88-94

Otto TC, Lande MD (2005) Adipose development: from stem cell to adipocyte. Crit Rev Biochem Mol Biol 40:229-242

Putz DM, Goldner WS, Bar RS, Haynes WG, Sivitz WI (2004) Adiponectin and c-reactive protein in obesity, type 2 diabetes, and monodrug therapy. Metabolism 53:1454-1461

Rasouli N, Kern PA (2008) Adipocytokines and the metabolic complications of obesity. J Clin Endocrinol Metab 93:S64-S73

Reimann M, Schutte AE, Schwarz PE (2007) Insulin resistance-the role of ethnicity: evidence from Caucasian and African cohorts. Horm Metab Res 39:853-857

Rieusset J, Bouzakri K, Chevillotte E, Ricard N, Jacquet D, Bastard JP, Laville M, Vidal H (2004) Suppressor of cytokine signaling 3 expression and insulin resistance in skeletal muscle of obese and type 2 diabetic patients. Diabetes 53:2232-2241

Sayeed MA, Khan AKA, Mahtab H, Ahsan KA, Banu A, Khanam PA, Ahrén B (2003) Leptin is reduced in lean subjects with type 2 diabetes in Bangladesh. Diabetes Care 26:547

Sivitz WI, Wayson SM, Bayless ML, Larson LF, Sinkey C, Bar RS, Haynes WG (2003) Leptin and body fat in type 2 diabetes and monodrug therapy. J Clin Endocrinol Metab 88:1543-1553

Skurk T, Alberti-Huber C, Herder C, Hauner H (2007) Relationship between adipocyte size and adipokine expression and secretion. J Clin Endocrinol Metab 92:1023-1033

Tatti P, Masselli L, Buonanno A, Di Mauro P, Strollo F (2001) Leptin levels in diabetic and nondiabetic subjects. Endocrine 15:305308

Wellen KE, Hotamisligil GS (2003) Obesity-induced inflammatory changes in adipose tissue. J Clin Invest 112:1785-1788

Yang Y, Lu HL, Zhang J, Yu HY, Wang HW, Zhang MX, Cianflone K (2006) Relationships among acylation stimulating protein, adiponectin and complement $\mathrm{C} 3$ in lean vs obese type 2 diabetes. Int J Obes 30:439-446

You T, Nicklas BJ (2008) Effects of exercise on adipokines and the metabolic syndrome. Curr Diab Rep 8:7-11

Yu JG, Javorschi S, Hevener AL, Kruszynska YT, Norman RA, Sinha M, Olefsky JM (2002) The effect of thiazolidinediones on plasma adiponectin levels in normal, obese, and type 2 diabetic subjects. Diabetes 51:2968-2974 